\title{
Prediction of Early Pregnancy Loss by Ultrasound Markers
}

\author{
Krupa H Shah ${ }^{1}$, Ruby Sultana ${ }^{2}$, Rema Nambiar ${ }^{3}$, Parvati Bhat ${ }^{4}$, Shashikala Bhat ${ }^{5}$
}

\begin{abstract}
Background: The purpose of the present study is to determine the performance of ultrasound markers in transvaginal scan (TVS) for the diagnosis of early pregnancy loss (EPL).

Materials and methods: This was a prospective observational study of 365 women undergoing initial TVS at between 6 weeks and 10 weeks of gestation. Demographic data were collected. Ultrasound parameters like gestational sac diameter (GSD), yolk sac diameter (YSD), crown rump length (CRL), and embryonic heart rate $(\mathrm{HR})$ were studied at the booking visit, and patients with an inconclusive scan report were asked for follow up after a week or 10 days.

Outcome: The measured outcome was first trimester (up to 14 weeks) pregnancy loss. Univariate analysis was done to compare both groups. Receiver-operating curve (ROC) was derived to find out the best cutoff value for studied parameters.

Results: Among 365 recruited patients, outcome was known for $91.7 \%(n=335)$. Of 335 analyzed subjects, 272 had ongoing pregnancy (group I) and 63 had miscarriage (group II). Univariate analysis showed significant association of age, symptoms like bleeding per vagina, suprapubic pain, and low GSD, CRL, HR, and difference of GSD CRL with EPL ( $p<0.05$ ). Detection of EPL was highest for HR below 5 th centile (57\%). Best cutoff values were derived for all parameters in ROC and it was found that GSD value of less than $20 \mathrm{~mm}$ had sensitivity of $60 \%$ with $77 \%$ specificity; for CRL of less than $7.5 \mathrm{~mm}$, it was $61 \%$ and $75 \%$; and for HR less than $85 \mathrm{bpm}$, it was $85 \%$ and $99 \%$, respectively. The GSD CRL difference of less than $8.5 \mathrm{~mm}$ was found highly sensitive (91\%) for prediction of EPL on ROC cutoff.

Conclusion:We conclude that calculating GSD, YSD, CRL, and HR at 6th-10th gestational weeks was significant in predicting gestational prognosis. Low embryonic HR ( $<85 \mathrm{bpm}$ ) was found to be an excellent performer in prediction of EPL through ROC. This study emphasizes further on the importance of performing obstetric ultrasound scan with precision and mindfulness.

Keywords: Early pregnancy loss, Fetal bradycardia, Small gestational sac, Ultrasound, Yolk sac miscarriage.

Journal of South Asian Federation of Obstetrics and Gynaecology (2019): 10.5005/jp-journals-10006-1685
\end{abstract}

\section{INTRODUCTION}

The diagnosis of abortion is an integral part of the antenatal care. With an advent of ultrasound scan (USS), diagnosis has become easy and accurate. In normal pregnancy, embryonic development is relatively uniform and the milestones on USS are gestational sac (GS), yolk sac (YS), embryonic pole, and cardiac activity. The early pregnancy loss (EPL) (spontaneous abortion $<10$ weeks) is classified as anembryonic miscarriage, YS miscarriage, and embryonic miscarriage. ${ }^{1}$ The gestational age and type of pregnancy demise help to understand etiopathogenesis of EPL. ${ }^{2}$

Accurate diagnosis is essential as to avoid inadvertent termination of viable pregnancy. The criteria for diagnosis of EPL are empty GS of greater than $25 \mathrm{~mm}$ and crown rump length (CRL) of greater than $7 \mathrm{~mm}$ without cardiac activity. ${ }^{1}$ Others are firstvisit scan with GS but without YS and repeat scan after 2 week suggesting absence of embryo and heartbeat. Similarly, first-visit scan with GS and YS but neither embryo nor heartbeat on interval scan. This emphasizes on the need for repeat US in order to comment on viability at interval of 7-14 days. ${ }^{1}$

The US parameters, biochemical markers, and demographic data have been published in literature for prediction of miscarriage. ${ }^{3-6}$ However, many of them are retrospective studies with contradictory results. Hence, the present study is carried out to know the performance of gestational sac diameter (GSD), yolk sac diameter (YSD), CRL, GSD-CRL difference, and heart rate (HR) for EPLs along with demographic factors impact.

\begin{abstract}
${ }^{1-5}$ Department of Obstetrics and Gynaecology, Dr TMA Pai Hospital, Melaka Manipal Medical College, Manipal Acedemy of Higher Education, Manipal, Karnataka, India

Corresponding Author: Krupa H Shah, Department of Obstetrics and Gynaecology, Dr TMA Pai Hospital, Melaka Manipal Medical College, Manipal Academy of Higher Education, Manipal, Karnataka, India, Phone: +91 9741736024, e-mail: hikrupa12@gmail.com

How to cite this article: Shah KH, Sultana R, Nambiar R, et al. Prediction of Early Pregnancy Loss by Ultrasound Markers. J South Asian Feder Obst Gynae 2019;11(3):185-189.
\end{abstract}

Source of support: Nil

Conflict of interest: None

\section{Materials and Methods}

The study was conducted at DrTMA Pai hospital, affiliated to Manipal Academy of Higher Education, Karnataka. The study was cleared by the ethical committee of Manipal University (IEC-286/2017), and design was the prospective observational cohort study. It was conducted from February 1, 2017, to September 2018. The calculated sample size was 294 . All consecutive pregnant women with pregnancy of uncertain viability between 6 weeks and 10 weeks of gestation were recruited. Women with unsure dates, multiple pregnancies, extrauterine pregnancy, chromosomal anomalies, elective termination of pregnancy, and lost to follow-up were excluded.

Maternal characteristics were noted after taking informed consent. Demographic data obtained were maternal age, parity,

(อ) The Author(s). 2019 Open Access This article is distributed under the terms of the Creative Commons Attribution 4.0 International License (https://creativecommons. org/licenses/by-nc/4.0/), which permits unrestricted use, distribution, and non-commercial reproduction in any medium, provided you give appropriate credit to the original author(s) and the source, provide a link to the Creative Commons license, and indicate if changes were made. The Creative Commons Public Domain Dedication waiver (http://creativecommons.org/publicdomain/zero/1.0/) applies to the data made available in this article, unless otherwise stated. 
married life, method of conception, previous history of abortion, associated symptoms (bleeding per vagina, suprapubic pain, backache), and comorbidities, if any.

Transvaginal scan was carried out with a 7.5-MHz transducer on HD Philips Clear View 350 to determine the pregnancy location, gestation age, and viability. All scans were performed by a single trained sonologist. Gestational age-specific parameters were noted at the booking visit, and patients with inconclusive scan report were asked to follow up after a week or 10 days. A GS is calculated as an average of three perpendicular diameters with calipers being placed at the inner edges of the trophoblast. A YS is calculated as an average of three perpendicular diameters with calipers being placed at inner edges of the YS walls. Simultaneously, variations in morphology (irregular GS, absent, calcified, or irregular YS) were noted. Crown rump length is measured in the sagittal plane with care being taken to exclude YS. The full length of embryo was measured when CRL was not discriminated due to small embryo length. Heart rate is calculated as beats per minute (bpm) in the frozen $M$ mode image by the distance between two heart waves. For the diagnosis of EPL, criteria laid by European society of human reproduction and embryology (ESHRE) were followed.? Women with inconclusive scan were asked for follow-up scans after 7-10 days.

After detection of intrauterine pregnancy, all women were subsequently followed up through antenatal visits and any event of suprapubic pain, backache, or bleeding per vagina was recorded. Pregnancy outcome at 14 completed weeks was divided into two groups. Group I had ongoing pregnancy beyond 14 weeks and group II with loss of pregnancy before 14 weeks of gestation in any form, i.e., anembryonic miscarriage (presence of only GS on USS done 1 week apart with no embryo), YS miscarriage (USS with presence of GS and YS with no embryo on two occasions 1 week apart), embryonic miscarriage (on USS done 1 week apart showing embryo with no cardiac activity), and missed miscarriage (spontaneous fetal demise before 14 weeks' gestation with or without prior demonstrable cardiac activity).

\section{Analysis}

Data were analyzed using the Scientific Package for Social Sciences (SPSS) 20 software. Analysis of categorical data was done by frequencies and compared by the Chi-square test. For continuous data, mean and standard deviation were derived for both groups and compared by an independent sample $t$ test. The $p$ value of less than 0.05 was considered to be statistically significant. The 5th, 50th, and 95th centile values for all parameters with respect to the period of gestation were derived and compared. To obtain HR centile value only, embryos with cardiac activity were considered. Similarly, for calculating CRL centile value, anembryonic and YS miscarriages were excluded. A receiver operating character curve was used to see the screening performance of each parameter under the study.

\section{Results}

A total of 365 women were included, and 335 women (91.7\%) could be followed up to 14 weeks. Among them, 272 women (group l) had viable pregnancy, and 63 women (group II) were diagnosed with nonviable pregnancy. Table 1 shows demographic characteristics in both the groups, where only age was found to be significantly associated with the incidence of EPL. The detection of viable pregnancy was earlier in ongoing pregnancies in comparison to the miscarriage group.

Table 2 suggests symptom association with EPL, where odds ratio (OR) of 10.2 and 7.7 are found for suprapubic pain and bleeding per vagina, respectively. We found significant association of diabetes mellitus and hypothyroidism with EPL.

Table 3 denotes the distribution of centile values in studied populations.

Table 4 suggests $\leq 5$ th centile values at different gestation in both the groups and performance of various parameters. The detection rate of EPL was highest for HR below 5 th centile (57\%).

Table 5 suggests area under the curve (AUC) was excellent for HR, which was 0.98 . The best cutoff values were derived for all parameters in receiver-operating curve and it was found that MSD value of less than $20 \mathrm{~mm}$ has sensitivity of $60 \%$ with $77 \%$ specificity; for CRL of less than $7.5 \mathrm{~mm}$, it was $61 \%$ and $75 \%$; for HR less than 85 bpm, it was $85 \%$ and $99 \%$; and for MSD-CRL difference of less than $8.5 \mathrm{~mm}$, it was $91 \%$ and $46 \%$, respectively

\section{Discussion}

The incidence EPL was 18\% (63/335) in our study. The maternal age was in range of 18-42 years. We found higher incidence of EPL at extremes of age, i.e., less than 20 and more than 35 years. It was $29.9 \%$ for age of greater than 35 years in the present study. A study by Papaioannou et al. ${ }^{3}$ found higher maternal mean age (33.5 years) for the miscarriage group and Wie et al. ${ }^{4}$ found $26.7 \%$ incidence for advanced maternal age ( $>35$ years). The association between maternal age and EPL reflects both biological mechanisms and forces of selection, ${ }^{8}$ meaning increased risk is attributable to chromosomal abnormalities and medical comorbidities at older age. We had only eight women of age less than 20 years, where EPL was noted in $37.5 \%$.

There was no significant association of EPL with parity, previous abortion, duration of marriage life, and mode of conception in our study, which was in accordance to the study by Makrydimas et al. ${ }^{6}$ In the literature, although there is an evidence, which supports the association of above-mentioned factors with miscarriage..$^{8-11}$

In the present study, we found, bleeding per vagina was associated significantly with miscarriage (OR-7.7). Makrydimas et al. noted that the incidence of miscarriage was 2.6 times higher among subjects with history of bleeding per vagina. ${ }^{6}$ Bleeding per vagina is an early feature of miscarriage. A study by Falco et al. found the rate of miscarriage in a women with the bleeding episode in a viable pregnancy was $10 \%$, whereas with nonviable pregnancy it was $40 \% .^{12}$ We found that suprapubic pain was significantly associated with EPL (OR-10.2). A study by Wie et al. ${ }^{4}$ found statistically significant higher incidence of miscarriage among woman with abdominal pain; similar results were noted in a study by Papaioannou et al. ${ }^{3}$ Back pain was found more in the miscarriage group, but it was statistically insignificantly in our study.

We observed that mean sac diameter (MSD) less than 5 th centile for GA was noticed in 18 of 365 (5\%) of the study group and resulted in abortion for 17 of 18 (94.4\%) pregnancies. However, it could predict only $26.9 \%$ of total EPL, which was in concordance with the study by Pappaioannou et al. ${ }^{3}$ (23.6\%) and Dickey et al. ${ }^{13}$ (23.9\%). The study by Wie et al. ${ }^{4}$ found a higher sensitivity of $46.7 \%$. We found the positive likelihood ratio of $67 \%$, suggesting EPL increases to when GS was less than 5th centiles. The restriction of GS means constriction of the coelomic cavity or the amniotic cavity or both 
Table 1: Demographic characteristics in both groups

\begin{tabular}{llll}
\hline Characteristics & Group I $(n=272)$ & Group II $(n=63)$ & $\begin{array}{l}\text { Test of significance } \\
(p \text { value })\end{array}$ \\
\hline $\begin{array}{l}\text { Married life (years) } \\
\text { Period of gestation (weeks) }\end{array}$ & $3.3 \pm 3.1$ & $3.8 \pm 3.6$ & 0.21 \\
$\begin{array}{l}\text { Age in years }(n) \\
\quad<20 \text { years }(8)\end{array}$ & $7.5 \pm 0.99$ & $8.1 \pm 1.11$ & 0.001 \\
$20-35$ years (303) & $5(1.8 \%)$ & $3(4.7 \%)$ & 0.02 \\
$>35$ years $(24)$ & $250(92.0 \%)$ & $53(83.4 \%)$ & \\
Parity $(n)$ & $17(6.2 \%)$ & $7(11.1 \%)$ & 0.67 \\
$\quad$ Nulliparous $(194)$ & $159(58.4 \%)$ & $35(55.5 \%)$ & \\
$\quad$ Parity $1 />(141)$ & $113(41.5 \%)$ & $28(44.5 \%)$ & \\
Prior miscarriage $(n)$ & & & \\
$\quad$ Present $(90)$ & $68(76.5 \%)$ & $22(24.4 \%)$ & 0.11 \\
Absent $(245)$ & $204(83.3 \%)$ & $41(16.7 \%)$ & \\
\hline
\end{tabular}

Table 2: The symptoms associated with early pregnancy loss

\begin{tabular}{llllc}
\hline Symptoms at presentation & Group I $(n=272)$ & Group II $(n=63)$ & p value & Odds ratio \\
\hline Suprapubic pain $(n=30)$ & $11(4 \%)$ & $19(30 \%)$ & 0.001 & 10.2 \\
Bleeding per vagina $(n=44)$ & $20(7.3 \%)$ & $24(38 \%)$ & 0.001 & 7.7 \\
Backache $(n=16)$ & $11(4 \%)$ & $5(7.9 \%)$ & 0.19 & NA \\
\hline
\end{tabular}

Table 3: The distribution of centile values of different variables in studied population

\begin{tabular}{lllll}
\hline Parameters & $<5$ th centile & 5th-95th centile & $>95$ th centile & p value \\
\hline Gestational sac in mm $(n=365)$ & 18 & 302 & 15 & $<0.0001$ \\
Group I $(n=272)$ & $1(0.3 \%)$ & $256(94.2 \%)$ & $15(5.5 \%)$ & \\
Group II $(n=63)$ & $17(27 \%)$ & $46(73 \%)$ & 0 & \\
Yolk sac in mm (325) & 29 & 269 & 27 & $<0.001$ \\
Group I (272) & $18(6.6 \%)$ & $236(86.8 \%)$ & $18(6.6 \%)$ & \\
Group II (53) & $11(21 \%)$ & $33(62.2 \%)$ & $9(16.8 \%)$ & \\
Crown rump length in mm (324) & 20 & 296 & 9 & $<0.0001$ \\
Group I (272) & $4(1.4 \%)$ & $259(95.2 \%)$ & $9(3.3 \%)$ & \\
Group II (52) & $16(31 \%)$ & $36(69 \%)$ & 0 & \\
Heart rate in bpm (293) & 13 & 271 & 9 & $<0.001$ \\
Group I (272) & $1(0.3 \%)$ & $262(96.3 \%)$ & $9(3.4 \%)$ & \\
Group II (21) & $12(57 \%)$ & $9(43 \%)$ & 00 & \\
\hline
\end{tabular}

and may be associated with subsequent growth impairment or oligohydramnios. ${ }^{6}$ The restricted growth of GS usually occurs after $3 \mathrm{~mm}$ size and can be attributed to the defective vascularization of chorio-decidua as seen in the conceptus with chromosomal abnormality. ${ }^{14}$ The higher value ( $>95$ th centile) observed in 15 of 365 (4.8\%) was not associated with pregnancy mishaps. However, it needs more data to prove its beneficial effect.

Since the developing embryo derives its nutrition from YS before placenta is formed, adequate size and functional YS is necessary. Too big ( $>5 \mathrm{~mm})$ and too small $(<2 \mathrm{~mm})$ YS hampers growth of embryo and thus leads to adverse outcome. Other abnormal morphological parameters are absent YS and irregular and calcified sac. ${ }^{15,16}$ We observed low value of YS in 29 of 335 (8.65\%) pregnancies and observed statistically significant association with EPL. Similar significance was observed with higher value of YSD. The YSD less than 5th and greater than 95th centile for GA had odds of 3.6 and 2.8, respectively, for prediction of EPL. This findings are consistent with several studies. 3,17,18
The small CRL ( $<5$ th centile for GA) was found in $6.2 \%$ in the study, resulted in $80 \%$ EPL rate. It had a sensitivity of $30.7 \%$, which was found to be $35 \%$ to $63 \%$ in various studies. ${ }^{19,20}$ Small CRL indicates either delayed conception or growth restriction but not producing immediate mishaps, hence with less detection power (low sensitivity). It provided odds of 29.7 and a positive likelihood ratio of $29 \%$ for the development of EPL with CRL less than 5th centile. The higher CRL was not found with higher pregnancy mishaps.

We observed $92 \%(16 / 20)$ abortion in the cohort of HR less than 5 th centile. The sensitivity of embryonic HR ( $<5$ th centile) for prediction of EPL was found to be 57\%, which was between 26 and $50 \%$ in various studies. ${ }^{3,6,21}$ The present study also confirms that embryonic HR has highest predictive value among different parameters. We had 15 of 21 (70\%) pregnancies in group II and 6 of $272(2.2 \%)$ pregnancies in group I with HR less than 100 . We found $70 \%$ incidence of miscarriage in HR less than $100 \mathrm{bpm}$. As the drop in HR beyond $100 \mathrm{bpm}$ increases probability of EPL, 
Table 4: Below 5th centile value at different gestation in both the groups and performance of various parameters

\begin{tabular}{|c|c|c|c|c|c|c|c|c|}
\hline Parameters (n) & $\begin{array}{l}\text { Period of } \\
\text { gestation }\end{array}$ & $\begin{array}{l}<5 \text { th centile } \\
\text { values (in mm) }\end{array}$ & $\begin{array}{l}\text { Sensitivity } \\
\text { (\%) }\end{array}$ & $\begin{array}{l}\text { Specificity } \\
(\%)\end{array}$ & $\begin{array}{l}\text { Negative } \\
\text { predictive } \\
\text { value (\%) }\end{array}$ & $\begin{array}{l}\text { Positive } \\
\text { predictive } \\
\text { value (\%) }\end{array}$ & $\begin{array}{l}\text { Positive } \\
\text { likelihood } \\
\text { ratio (\%) }\end{array}$ & $\begin{array}{l}\text { Negative } \\
\text { likelihood } \\
\text { ratio (\%) }\end{array}$ \\
\hline MSD in mm (18) & 6-7 weeks & 10 & 26 & 99.6 & 94.4 & 85.4 & 67.2 & 0.73 \\
\hline Group I (1) & $7-8$ weeks & 12 & & & & & & \\
\hline \multirow[t]{2}{*}{ Group II (17) } & 8-9 weeks & 14 & & & & & & \\
\hline & $>9$ weeks & 17.7 & & & & & & \\
\hline YSD in mm (29) & 6-7 weeks & 2 & 20.7 & 93.3 & 37.9 & 85 & 3.13 & 0.84 \\
\hline Group I (18) & $7-8$ weeks & 3 & & & & & & \\
\hline \multirow[t]{2}{*}{ Group II (11) } & $8-9$ weeks & 2 & & & & & & \\
\hline & $>9$ weeks & 2.2 & & & & & & \\
\hline CRL in $\mathrm{mm}(20)$ & 6-7 weeks & 2 & 30.7 & 98.5 & 80 & 88.1 & 21.9 & 0.70 \\
\hline Group I (4) & $7-8$ weeks & 4 & & & & & & \\
\hline \multirow[t]{2}{*}{ Group II (16) } & $8-9$ weeks & 5 & & & & & & \\
\hline & $>9$ weeks & 5.5 & & & & & & \\
\hline HR in bpm (13) & 6-7 weeks & 65 & 57 & 99.6 & 92.3 & 96.7 & 142.5 & 0.43 \\
\hline Group I (1) & $7-8$ weeks & 95 & & & & & & \\
\hline \multirow[t]{2}{*}{ Group II (12) } & 8-9 weeks & 102 & & & & & & \\
\hline & >9 weeks & 74 & & & & & & \\
\hline
\end{tabular}

Table 5: The best cutoff and performance for studied parameters on AUC

\begin{tabular}{|c|c|c|c|c|c|c|}
\hline Parameter & $A \cup C(95 \% C I)$ & $S E^{*}$ & Best cutoff & Sensitivity (\%) & Specificity (\%) & $p$ value \\
\hline MSD & $0.78(0.9-1)$ & 0.03 & $<20 \mathrm{~mm}$ & 60 & 77 & 0.0001 \\
\hline YSD & $0.60(0.4-0.7)$ & 0.05 & $<3.4 \mathrm{~mm}$ & 55 & 79 & 0.010 \\
\hline CRL & $0.75(0.6-0.8)$ & 0.03 & $<7.5 \mathrm{~mm}$ & 61 & 75 & 0.001 \\
\hline $\mathrm{HR}$ & $0.98(0.9-1)$ & 0.01 & $<85 \mathrm{bpm}$ & 85 & 99 & 0.001 \\
\hline MSD-CRL & $0.73(0.6-0.8)$ & 0.04 & $<8.5$ & 91 & 46 & 0.001 \\
\hline
\end{tabular}

hence all reported bradycardia needs to be evaluated after 7-10 days for the outcome.

The small GS syndrome is a less than $5 \mathrm{~mm}$ difference between GS and CRL. ${ }^{22}$ This sign is rare, but its presence indicates higher chances of EPL, up to $90 \%$. MSD-CRL difference of less than $5 \mathrm{~mm}$ was found in $4 \%$ of the total sample and had a sensitivity of $57 \%$ in our study. Mean MSD-CRL was $13.8 \pm 4.3$ vs $10.1 \pm 4.6 \mathrm{~mm}$, which was significantly different $(p<0.05)$ in both the groups. Similar results were observed in study by Bromley et al. and Ahemd et al. ${ }^{5,22}$ As GS and CRL are gestation-dependent, hence the delta value could have been more specific for prediction than the original value at different gestations, which we have not analyzed.

Univariate analysis showed significant association of age, symptoms like bleeding per vagina, suprapubic pain and low MSD, $\mathrm{CRL}, \mathrm{HR}$, and difference of MSD-CRL with EPL ( $p$ value $<0.05$ ). Hence, binary logistic regression analysis was applied, and it was found that the prediction of miscarriage had inverse relation with MSD (OR-0.85), HR (OR-0.9), and CRL (OR-0.79). We couldn't demonstrate significant correlation with bleeding per vagina, abdominal pain, and YSD on binary logistic regression. The results were consistent with the study by Papaioannou et al., which demonstrated that prediction of miscarriage was inversely related to MSD (OR-0.84), CRL (OR-0.79), and HR (OR-0.96). ${ }^{3}$ We also constructed ROC, and prediction of miscarriage for all the parameters under study was good to excellent, except for the YS. We were able to derive the best cutoff values for the study parameters. Different studies with cutoff values for ultrasound parameters in the several studies are mentioned in Table $6,{ }^{19,23}$ which is comparable to our study.

\section{Limitation and Strengths}

We acknowledge that our sample size was limited to determine accurately the impact of young age and various demographic factors for development of EPL. We believe that this is the first ever study that provided centile values for gestational age between 6 weeks and 10 weeks in the region of costal Karnataka. We hope that the emerged figure from the study would help in the management of antenatal patients with risk factors. In the absence of above risk factors, EPL is unlikely, as it was $2.1 \%$ in our study.

\section{Conclusion}

In suspected cases of EPL, review scan after 7-10 days helps to avoid error in the diagnosis of viable pregnancy. Similarly, reassessment is advocated for pregnancies with extremes of US parameters in order to diagnose pregnancy mishaps earliest. An approach should include combined assessment of demographic characters and ultrasound parameters for prediction of EPL. The low HR was found to be a more sensitive predictor and an excellent performer in prediction of EPL on ROC.

\section{Clinical Significance}

The elderly age pregnancies are at higher risk of abortion; hence, frequent monitoring is required even in first trimester, more so, with 
Table 6: Comparison of different study parameters on ROC

\begin{tabular}{llllll}
\hline Parameters & Study & AUC & Cutoff value & Sensitivity (\%) & Specificity (\%) \\
\hline MSD & El-Mekkawi et al. & 0.94 & $14 \mathrm{~mm}$ & 96 & 74 \\
& Falco et al. & 0.67 & $<19 \mathrm{~mm}$ & 49 & 82 \\
& Present study & 0.78 & $<20 \mathrm{~mm}$ & 60 & 77 \\
CRL & El-Mekkawi et al. & 0.55 & $5.5 \mathrm{~mm}$ & 58 & 60 \\
& Falco et al. & 0.64 & $14 \mathrm{~mm}$ & 73 & 52 \\
HR & Present study & 0.75 & $<7.5 \mathrm{~mm}$ & 61 & 92 \\
& El-Mekkawi et al. & 0.95 & $111 \mathrm{bpm}$ & 92 & 90 \\
& Falco et al. & 0.57 & $<-1.2 \mathrm{SD}$ & 30 & 95 \\
MSD-CRL & Present study & 0.98 & $<85 \mathrm{bpm}$ & 85 & 89 \\
& Falco et al. & 0.64 & $<0.5 \mathrm{SD}$ & 39 & 46 \\
\hline
\end{tabular}

extreme low values of ultrasound parameters. The symptoms like bleeding per vagina and suprapubic pain need timely intervention and frequent follow-up to reduce pregnancy mishaps. The detection of the fetal bradycardia is an ominous sign; hence, timely follow-up is necessary. An embryonic low $\mathrm{HR}$ is highly sensitive for prediction of EPL, then parameters like GSD, CRL, and GSD CRL difference.

\section{References}

1. Kolte AM, Bernardi LA, et al. Terminology for pregnancy loss prior to viability: A consensus statement from the ESHRE early pregnancy special interest group. Hum Reprod 2015;30(3):495-498. DOI: 10.1093/ humrep/deu299.

2. Simpson JL. Causes of Fetal Wastage. Clin Obstet Gynecol 2007;50(1). DOI: 10.1097/GRF.0b013e31802f11f6.

3. Papaioannou GI, Syngelaki A, et al. Ultrasonographic prediction of early miscarriage. Hum Reprod 2011;26(7):1685-1692. DOI: 10.1093/ humrep/der130.

4. Wie $\mathrm{JH}$, Choe $\mathrm{S}$, et al. Sonographic parameters for prediction of miscarriage role of 3-dimensional volume measurement. JUltrasound Med 2015;34(10):1777-1784. DOI: 10.7863/ultra.15.14.09012.

5. Jakal A, Görgen $\mathrm{H}$, et al. The Role of Ultrasound in Early Pregnancy in Prediction of Miscarriages 2007;15:20-25.

6. Makrydimas G, Sebire NJ, et al. Fetal loss following ultrasound diagnosis of a live fetus at 6-10 weeks of gestation. Ultrasound Obstet Gynecol 2003;22(4):368-372. DOI: 10.1002/uog.204.

7. Huchon C, Deffieux X, et al. Pregnancy loss: French clinical practice guidelines. Eur J Obstet Gynecol Reprod Biol 2016;201:18-26.

8. Nybo Andersen AM, Wohlfahrt J, et al. Maternal age and fetal loss: population based register linkage study. BMJ 2000;320(7251): 1708-1712. DOI: 10.1136/bmj.320.7251.1708.

9. Levin AA, Schoenbaum SC, et al. Association of induced abortion with subsequent pregnancy loss. JAMA 1980;243(24):2495-2499. DOI: 10.1001/jama.1980.03300500021020.

10. Winter E, Wang J, et al. Early pregnancy loss following assisted reproductive technology treatment. Hum Reprod 2002;17(12): 3220-3223. DOI: 10.1093/humrep/17.12.3220.

11. Hu X, Miao M, et al. Reproductive Factors and Risk of Spontaneous Abortion in the Jinchang Cohort. Int J Environ Res Public Health 2018;15(11):2444. DOI: 10.3390/ijerph15112444.

12. Falco $P$, Milano $V$, et al. Sonography of pregnancies with first-trimester bleeding and a viable embryo: a study of prognostic indicators by logistic regression analysis. Ultrasound Obstet Gynecol 1996;7(3): 165-169. DOI: 10.1046/j.1469-0705.1996.07030165.x.

13. Dickey RP, Gasser R, et al. Relationship of initial chorionic sac diameter to abortion and abortus karyotype based on new growth curves for the 16th to 49th post-ovulation day. Hum Reprod 1994;9(3):559-565. DOI: 10.1093/oxfordjournals.humrep.a138544.

14. Oh JS, Wright G, et al. Gestational sac diameter in very early pregnancy as a predictor of fetal outcome. Ultrasound Obstet Gynecol 2002;20(3):267-269. DOI: 10.1046/j.1469-0705.2002.00774.x.

15. Adiga P, Selvi C, et al. Evaluation of Yolk Sac Diameter and Embryonic Heart Rate as Prognostic Factors of Gestational Outcome in Early Singleton Pregnancies. Sch J App Med Sci 2015;3:543-550.

16. Rodgers SK, Chang C, et al. Normal and Abnormal US Findings in Early First-Trimester Pregnancy: Review of the Society of Radiologists in Ultrasound 2012 Consensus Panel Recommendations. Radiographics 2015;35(7):2135-2148. DOI: 10.1148/rg.2015150092.

17. Tan S, Ipek A, et al. Irregular yolk sac shape: is it really associated with an increased risk of spontaneous abortion? J Ultrasound Med 2011;30(1):31-36. DOI: 10.7863/jum.2011.30.1.31.

18. Varelas FK, Prapas NM, et al. Yolk sac size and embryonic heart rate as prognostic factors of first trimester pregnancy outcome. Eur J Obstet Gynecol Reprod Biol 2008;138(1):10-13. DOI: 10.1016/ j.ejogrb.2007.06.023.

19. Bottomley C, Van Belle V, et al. Accurate prediction of pregnancy viability by means of a simple scoring system. Hum Reprod 2013;28(1):68-76. DOI: 10.1093/humrep/des352.

20. Abuelghar WM, Fathi HM, et al. Can a smaller than expected crown-rump length reliably predict the occurrence of subsequent miscarriage in a viable first trimester pregnancy? J Obstet Gynaecol Res 2013;39(10):1449-1455. DOI: 10.1111/jog.12082.

21. Altay MM, Yaz H, et al. The assessment of the gestational sac diameter, crown-rump length, progesterone and fetal heart rate measurements at the 10th gestational week to predict the spontaneous abortion risk. J Obstet Gynaecol Res 2009;35(2):287-292. DOI: 10.1111/j.14470756.2008.00927.x.

22. Bromley $B$, Harlow $B L$, et al. Small sac size in the first trimester: a predictor of poor fetal outcome. Radiology 1991;178(2):375-377. DOI: 10.1148/radiology.178.2.1987595.

23. D'Antonio F, Khalil A, et al. Embryonic growth discordance and early fetal loss: the STORK multiple pregnancy cohort and systematic review. Hum Reprod 2013;28(10):2621-2627. DOI: 10.1093/humrep/ det277. 